\title{
Diversifying online rheumatology education options in the era of COVID-19
}

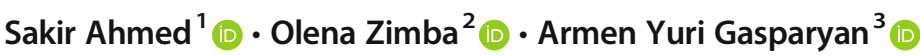 \\ Received: 8 October 2020 / Revised: 8 October 2020 / Accepted: 13 October 2020 / Published online: 19 October 2020 \\ (C) International League of Associations for Rheumatology (ILAR) 2020
}

We are grateful to Mehul Sinha and co-authors for their interest [1] in our article on online education in the era of COVID19 [2]. They have reiterated the point that online education may lack emotional connect and suggested how to get around it. Also, they have suggested psychometric modelling for personalized learning. This may be the ultimate expression of Huxley's dream of free and empowering education [2]. However, this is a resource intense strategy, and there is an urgent need to balance resources with demand least online education does not become limited to a privileged few [3].

At the individual level, the onus is both on the teacher and the students not to limit their interactions to online classes only. Strategies recommended for this include formation of small groups of students for peer support, interaction via phone calls, emails or messages and regular feedback evaluation [4].

At university and national level, Mehul Sinha and coauthors have provided examples of Massive Open Online Courses (MOOCs). Unfortunately, numerous educational resources, textbooks and journals in rheumatology are still locked behind the closed publishing model that limits dissemination of scientific information via social media and other

Armen Yuri Gasparyan

a.gasparyan@gmail.com

Sakir Ahmed

sakir005@gmail.com

Olena Zimba

sakir005@gmail.com

1 Department of Clinical Immunology \& Rheumatology, Kalinga Institute of Medical Sciences (KIMS), KIIT University, Bhubaneswar 751024, India

2 Department of Internal Medicine No. 2, Danylo Halytsky Lviv National Medical University, Lviv, Ukraine

3 Departments of Rheumatology and Research and Development, Russells Hall Hospital, Dudley Group NHS Foundation Trust (Teaching Trust of the University of Birmingham, UK), Pensnett Road, Dudley, West Midlands DY1 2HQ, UK emerging open channels [5]. Open-access tools and platforms have global visibility and influence, justifying the shift towards open-access publishing [6]. If rheumatology societies open up their educational sources, it may have a huge global impact. Global and regional rheumatology societies have already taken initiatives to launch open-access journals and arrange online meetings. Another perspective initiative can be publishing new open-access textbooks incorporating emerging topics in rheumatology such as those related to the COVID-19 pandemic and anti-rheumatic drugs repurposing. The new generation of online textbooks can be enriched with digital health and teleconsultation materials.

In our index article, we have exemplified diverse online education initiatives of some, but not all, rheumatology societies. Definitely, there are many other options variably employed by regional and national societies, depending on their research infrastructure, publication outlets and networking [7]. There is a need to build an international network across societies that can incorporate unexploited resources and ensure equitable distribution of rheumatology education.

Arguably, diversifying online education methods is required to meet various challenges across the globe. Didactic classroom lectures are no longer viable options. Social media platforms, webinar software, online research and consultation websites are now offering much more for all rheumatology fellows. The challenge is not just to incorporate human touch in online resources, but how to be inclusive and still diversify as per individual needs.

\section{Compliance with ethical standards}

Disclosures None.

\section{References}

1. Sinha M, Agarwal V, Gupta L (2020) Human touch in digital education - a solution. Clin Rheumatol 
2. Ahmed S, Zimba O, Gasparyan AY (2020) Moving towards online rheumatology education in the era of COVID-19. Clin Rheumatol. $\mathrm{https} / / /$ doi.org/10.1007/s10067-020-05405-9

3. [No authors listed] (2020) Online learning cannot just be for those who can afford its technology. Nature 585(7826):482 https://doi.org/ 10.1038/d41586-020-02709-3

4. Gewin V (2020) Five tips for moving teaching online as COVID-19 takes hold. Nature 580(7802):295-296. https://doi.org/10.1038/ d41586-020-00896-7

5. Gasparyan AY, Yessirkepov M, Voronov AA, Koroleva AM, Kitas GD (2019) Comprehensive approach to open access publishing: platforms and tools. J Korean Med Sci 34(27):e184. https://doi.org/10. 3346/jkms.2019.34.e184
6. Mašić I, Begić E, Donev DM, Gajović S, Gasparyan AY, Jakovljević M, Milošević DB, Sinanović O, Sokolović Š, Uzunović S, Zerem E (2016) Sarajevo declaration on integrity and visibility of scholarly publications. Croat Med J 57(6):527-529. https://doi.org/10.3325/ cmj.2016.57.527

7. Gheita TA, Eesa NN (2019) Rheumatology in Egypt: back to the future. Rheumatol Int 39(1):1-12. https://doi.org/10.1007/s00296018-4192-0

Publisher's note Springer Nature remains neutral with regard to jurisdictional claims in published maps and institutional affiliations. 